\title{
A importância da indumentária nas pinturas de castas: um estudo do quadro "Castas" de Luis de Mena
}

\section{Giovanna de Assis Bareli}

DOI: 10.11606/issn.2318-8855.v10i1p484-504

Resumo: As pinturas de castas são produto da Sociedade de Castas, uma política colonial que visava a hierarquização e estratificação da sociedade, baseada na diferenciação racial, com predominância principalmente na metade do século XVIII. A indumentária presente nesses quadros são reflexos dos códigos vestuários, cunhados pelas leis coloniais, que auxiliavam na percepção da identidade e dos mecanismos de diferenciação entre os indivíduos, sendo uma forma visual de reproduzir as relações hierárquicas da sociedade. Nesse sentido, simbolizam uma manifestação identitária e refletem o imaginário social da Nova Espanha. O presente artigo propõe, a partir da análise do quadro "Castas" (1750), de Luis de Mena, uma reflexão sobre o papel da representação da indumentária no gênero das pinturas de castas. Essa análise se utiliza das perspectivas da História Cultural para a compreensão das formas simbólicas e dos discursos presentes nas obras de arte.

Palavras-chaves: : Indumentária; Pintura de Castas; Quadro "Castas"; Sociedade de Castas.

* Graduanda em História pela Universidade Estadual de Campinas (Unicamp) e bolsista de Iniciação Científica pela Fundação de Amparo à Pesquisa do Estado de São Paulo (FAPESP), sob orientação do Prof. Dr. Leandro Karnal. E-mail para contato: 


\section{artigos}

\section{A Importância da Indumentária nas Pinturas de Castas}

\section{O gênero pinturas de Castas}

O gênero de pintura de castas surgiu ante a necessidade de "diferenciar as misturas raciais em grupos e subgrupos, a partir do momento que as misturas entre as populações de origem europeia, indígena e africana atingiram tamanho grau de diversidade" (GRUZINSKI, 2001, p. 50). Nesse sentido, refletem um discurso de hierarquização e estratificação da sociedade, a chamada Sociedade de Castas, que era embebida pela teoria de limpieza de sangre e calidad. Em outras palavras, um sistema que qualificava com base nos fatores sociais, culturais e econômicos do grupo, considerando a ocupação, nascimento, reputação e os vínculos pessoais do indivíduo (BOYER, 1997, p. 64-65; SCHWARTZ, 1995, p. 186).

Esse gênero ganha notoriedade em todo o século XVIII, mas tem o seu auge a partir das mudanças na segunda metade do setecentos. As obras incluídas neste gênero são diversas, pois, por serem um produto de grande repercussão, foram realizadas por diferentes pintores, do menor ao maior alinhamento técnico e de diferentes maneiras, mas quase todas realizando séries de 16 a 20 castas.

Em geral, trazem uma família de cada casta, inserida em seu cotidiano e com adereços simbólicos determinados pela sua posição sociorracial. O filho dessa união gera a próxima cena, formando uma progressão racial, fruto da mestiçagem entre espanhóis, indígenas e negros. Dessa maneira, quanto maior o cruzamento interracial, menor o status socioeconômico da família. Podem exibir, como complemento, objetos ou elementos da fauna e flora que auxiliam na composição do discurso do quadro. Cada unidade presente nas obras, nesse sentido, contribui para o discurso da mesma: a indumentária dialoga com a questão das leis coloniais de vestimentas que cada casta poderia utilizar como demonstração da sua origem e 


\section{artigos}

\section{Giovanna de Assis Bareli}

posição social. A iconografia complementar muitas vezes remetia à uma visão positiva da colônia, seja mostrando as especificidades positivas, como a arquitetura, seja para demonstrar a abundância da Colônia, como um lugar fértil e rico (KATZEW, 2004, p. 160-161).

Portanto, os objetivos dos quadros são expor pictoricamente a progressão de raças, atributos morais de cada casta e a flora e fauna do México; em um ambiente de ordem desejável em que cada casta ocupa seu espaço social, mas com a possibilidade de mudança para as futuras gerações, mediante casamento com o tipo adequado de mestiçagem - o branco, o espanhol. Para isso, se utilizam de uma visão estigmatizada e baseada nas leis de distinção colonial, sem necessariamente refletir a realidade da Nova Espanha (KATZEW, 2004, p. 114).

Apresentam também questões importantes para o momento da sua criação, como a Reforma Bourbônica ${ }^{1}$, que representou uma virada fundamental para o gênero: antes, quase todas as castas eram retratadas de uma maneira positiva e sem muita distinção, sendo todas representadas de uma maneira luxuosa. Mas, na metade do século XVIII, com a reforma, passaram a inserir fatores de distinções, representar brigas, violência e embriaguez. Os fatores mais negativos ficaram a cargo das castas mais baixas, sendo essa uma demonstração da intenção simbólica e ideológica do gênero como contribuinte para regulamentar uma sociedade que, pelo menos em teoria, era ligada à hierarquia e estratificação (KATZEW, 2014, p. 144-146).

Portanto, as pinturas de castas são um importante documento histórico e cultural pelas referências ao contexto histórico, às práticas sociais e pela visualização

\footnotetext{
${ }^{1}$ Reformas administrativas e econômicas do sistema colonial espanhol ocorridas durante os reinados da Casa de Bourbon, durante o século XVIII. Nas colônias, elas implicaram na reestruturação da administração colonial, na restituição do poder da classe privilegiada local, da Igreja e das receitas coloniais. Buscavam uma recolonização e um imperialismo renovado que reduzia a participação criolla no governo.
} 


\section{artigos}

\section{A Importância da Indumentária nas Pinturas de Castas}

de parte do imaginário social referente às políticas classificatórias, sendo, também, uma fonte de pesquisa para o estudo do pensamento e comportamento do século XVIII na Nova Espanha. Como parte dessa visualização, a cultura material inserida nos quadros contribui para o estudo do pensamento colonial e auxilia na construção da diferenciação das castas (VOSS, 2015, p.253). No caso específico das vestimentas:

O fato de Cabrera, assim como muitos outros artistas que pintaram ciclos de casta depois dele, usarem roupas como um indicador de classe socioeconômica, ecoa a preocupação generalizada no México e na Espanha em relação à perda das fronteiras sociais. A estratificação social fica assim clara nessas pinturas por meio da diferenciação das roupas (KATZEW, 2004, p.109, tradução nossa). ${ }^{2}$

A indumentária, sendo assim, é um elemento essencial para a composição desses quadros.

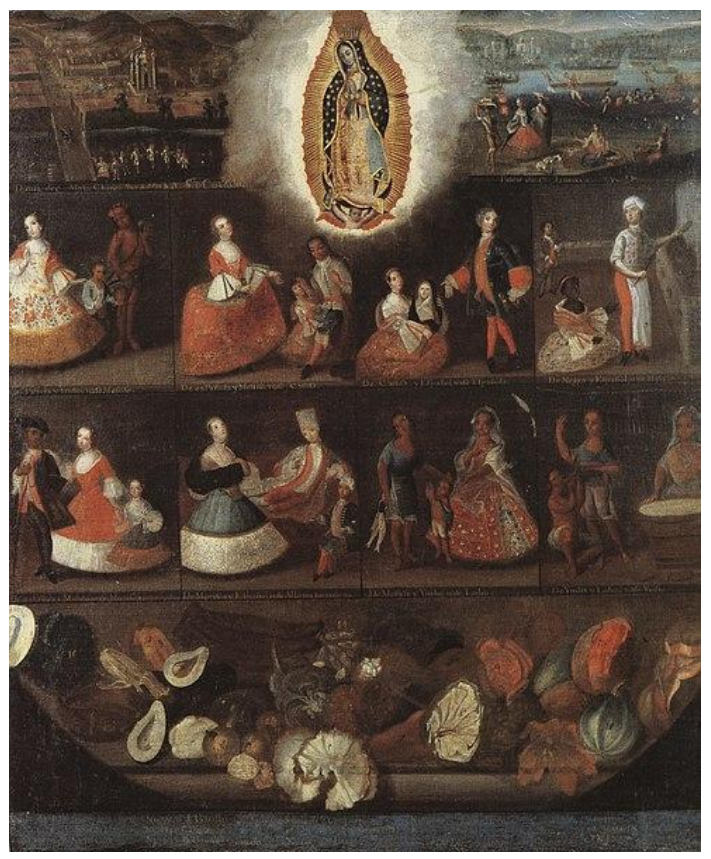

\footnotetext{
${ }^{2}$ No original: "The fact that Cabrera, as well as many other artist Who painted casta cycles after him, used clothing as an indicator of socioeconomic class echoes the pervasive concern in Mexico and Spain regarding the loss of social boundaries. Social stratification is thus rendered clear in these paintings through the differentiation of clothes"
} 


\section{artigos}

\section{Giovanna de Assis Bareli}

Imagem 1: A Indumentária no quadro "Castas" de Luis de Mena. Fonte: MENA, Luis. "Castas" 1750, óleo sobre tela. $119 \times 103 \mathrm{~cm}$. Collection of the Museo de America, Madrid (inventory number 00026).

O quadro "Castas" foi produzido no limiar das mudanças do gênero, em 1750, por um artista desconhecido na época, Luis de Mena. É um ícone da pintura de castas por trazer um elemento único e diferenciador: a Virgem de Guadalupe no centro da obra.

A forma de leitura utilizada é a recorrente na análise desse quadro ${ }^{3}$, sendo lida de cima para baixo, da direita para a esquerda. Tal lógica segue também a convenção das pinturas de castas, que por representar a progressão racial, vai do mais desejado para o menos desejado. Pensando nessa questão, isso explica porque Guadalupe está colocada na parte superior. É o elemento mais importante e de maior destaque, seja pelas cores mais fortes, seja pela representação em uma mardola com névoa branca em volta que delimita e chama atenção para a figura sacra. Ela é a chave de compreensão dessa leitura (CLINE, 2015, p.224), um fator que também se diferencia dos outros quadros de pintura de castas, que possuem como principal a representação da hierarquia entre as classes. Entretanto, essa questão não deve ser minimizada, sendo Guadalupe compreendida em relação às figuras de mestiçagem. Sendo assim, a apreensão do quadro se dá pela questão do criollismo, um movimento de exaltação da identidade criolla, ou seja, espanhóis que nasceram na colônia e que desejavam adquirir um espaço social parecido com os dos peninsulares. Tal movimento intentou por elementos únicos de distinção entre os que nasceram na colônia e os peninsulares, encontrando tal aspecto na devoção à Virgem de Guadalupe. A figura sacra se torna mãe, protetora, símbolo e patrona do México, o que os levaria a um futuro excepcional, por serem o povo escolhido pela Virgem

\footnotetext{
${ }^{3}$ Utilizadas por autores que analisaram o quadro (Cf. OLIVEIRA, 2018; CLINE, 2015).
} 


\section{artigos}

\section{A Importância da Indumentária nas Pinturas de Castas}

(FLORESCANO, 1994, p. 444).

Dito isso, os outros elementos que compõem o quadro "Castas" são: ao lado da figura de Guadalupe, há duas representações da vida colonial, na esquerda “Dansa de Matachines que asen a N. Sra d. Guadalupe", e na direita "Paseo de Jamayca". Os elementos da parte superior trazem componentes importantes da indumentária, como na cena do canto superior esquerdo, em que há um grupo de dançarinos em primeiro plano: uma mulher, com um vestido rodado branco e vermelho, e sete homens com trajes da mesma cor. Essas roupas remetem à danza mattachine, ou seja, "uma dança alegre e grotesca, que consiste em golpear uns aos outros com uma espada de madeira e golpes no ar" (ESTRADA DE GERLERO, 1994, p.90, tradução nossa) $)^{4}$.

Já na cena do canto superior direito, diversas castas estão no mesmo ambiente, o que traz visualmente a diferença de traje e ações das personagens: espanhóis em vestes bourbônicos passeiam em uma jangada; um casal anda pela margem, sendo que a mulher utiliza um vestido espanhol e o homem um longo chapéu de palha e uma túnica, que pode ser um huipil, elementos representativos de um indígena (VOSS, 2015, p.257; YTURBIDE; GAGE, 1990, p. 77). Há um vendedor ambulante com roupas simples carregando sua mercadoria na cabeça e duas mulheres que trabalham sentadas próximo ao espectador. Aqui, itens exclusivos das castas aparecem, como o chapéu, o huipil e os trajes espanhóis que caracterizam visualmente as personagens, sendo que a relação da ação que cada um realiza está ligado à roupa que veste: aqueles que trabalham utilizam roupas mais leves e simples; e os que passeiam utilizam roupas refinadas e que são características da sua

\footnotetext{
${ }^{4}$ No original: "una danza alegre y grotesca, consistente en golpearse unos a otros con espadas de palo y vejigas de aire"
} 


\title{
artigos
}

\section{Giovanna de Assis Bareli}

posição sociorracial. Um fator relevante é que os espanhóis que se encontram no quadro estão em uma "paseo", um entretenimento da elite, que gostava de estar nesses lugares como uma forma de demonstrar a sua diferença e selar os seus privilégios (CARRERA, 2003, p. 115).

As cenas de castas, ao centro da composição, são a segunda parte mais fundamental da obra, uma vez que revelam relacionamentos entre espanhóis e indígenas, espanhóis e negros e entre negros e indígenas. A categorização resultante aparece na cena seguinte, seguindo uma linha lógica entre as mestiçagens, totalizando oito famílias. A indumentária e os espaços em que as personagens estão inseridas auxiliam na distinção entre elas, além da tonalidade da pele.

Na primeira cena, "de española y indio nace mestizo", a mãe traja um típico vestido de espanhola, com ornamentos ricos e floral, manga bufante com renda e um xale vermelho nos ombros. Sua roupa é um grande exemplo da moda Bourbônica ${ }^{5}$, embebida na influência francesa, sendo que os vestidos eram rodados até o chão e com um corpete ajustado ao corpo (VOSS, 2015, p. 257), com:

\begin{abstract}
grandes decotes cobertos por musselina leve, o corpete apertado terminava em um ângulo agudo e rendas largas saíam das bordas das mangas. Todos os vestidos, mesmo os de ricos bordados em seda chinesa ou europeia, eram enfeitados com laços, guarnições e tranças douradas e prateadas. O saiote robusto mostrava o sapato, onde brilhavam as fivelas de diamante. Os penteados eram adornados com laços, joias e penas; joias foram usadas extensivamente, especialmente as pérolas (YTURBIDE; GAGE, 1990, p.76,
\end{abstract}

\footnotetext{
5 "in the 1700s, the advent of the Bourbon monarchy brought visual inspection to the forefront of governmentality, and the Spanish government increased surveillance of bodily practices such as clothing. There was rising concern that it was becoming impossible to distinguish the different social groups that composed the legal estates. A climate of suspicion grew among colonial elites, centered on the fear that some people of Moorish and African heritage were successfully passing as Spaniards. Concern about racial passing was further intensified by heightened attempts to enforce estate-based tax codes and tribute requirements. Clothing, which lent itself to concealing and transforming identities, was a focal point of these anxieties" (VOSS, 2015, p. 256).
} 


\section{A Importância da Indumentária nas Pinturas de Castas}

tradução nossa) .

Tal característica está presente em todas as vestimentas femininas do quadro, como será apresentado ao longo do texto. Há detalhes e composições que diferenciam todos os vestidos, tornando-os singulares e representando a diferença de cada família.

Ainda sobre a primeira cena, o filho, vestido à moda, carrega um pequeno arco e flecha, assim como o pai. Esse, por sua vez, alude para a representação de um indígena chichimeca7: descalço, com ornamento de plumas na cabeça, cabelos compridos e praticamente nu, somente com uma túnica cobrindo sua parte íntima. Este indígena era a representação simbólica de um bárbaro e, por estar com uma mulher da mais alta casta, deve ser lido como uma alegoria entre o encontro e colonização da América (índio) e da Europa (espanhola), o que não era incomum nas obras da época (CLINE, 2015, p. 226-227).

A espanhola da segunda cena, “De española y mestizo, nace castizo" também veste trajes típicos, trazendo elementos complementares, como o sapato preto e detalhes em sua roupa, que remetem a questão de acabamento, como os laços azuis que ligam as mangas ao resto do vestido. A questão do refinamento, do acabamento e da escolha de tecidos finos e de bom caimento contribuíam como um fator de enriquecimento do vestuário feminino e masculino (VOSS, 2015, p.261).

\footnotetext{
${ }^{6}$ No original: “(...) grandes escotes iban cubiertos de ligeras muselinas; el ajustado corpiño terminaba en un ángulo agudo, y de los bordes de las mangas salían anchos encajes. Todos los vestidos, incluso los de ricos brocados de seda chinos o europeos, se adornaban con lazos, pasamanerías y galones de oro y plata. La ampona enagua dejaba lucir el zapato, donde brillaban las hebillas de diamantes ('ebillas de pies'). Los peinados se adornaban con lazos, alhajas y plumas; las joyas eran usadas con profusión, especialmente las perlas".

7 Os indígenas chichimeca são representados dessa maneira como uma referência a sua "barbárie". Eram um grupo que viviam ao norte da Cidade do México, sendo vistos como uma etnia de difícil colonização para astecas e espanhóis (Cf. ESTRADA DE GERLERO, 1996).
} 


\section{artigos}

\section{Giovanna de Assis Bareli}

Essa personagem contempla a Virgem de Guadalupe, que ocupa parcialmente o canto direito superior, sendo possível compreender tal olhar como um suplício (CLINE, 2015, p. 232), por sua filha estar em uma posição menor, o que poderá ser visto em outros momentos nessa representação: na cena três e seis. A filha do casal porta o mesmo estilo de roupa que sua mãe, algo comum nas representações do gênero (YTURBIDE; GAGE, 1990, p. 77). Já a figura masculina tem seus cabelos no estilo melena ${ }^{8}$, manifestando orgulho da sua descendência de indígena hispanizado (CLINE, 2015, p. 228).

Na terceira cena, "de castiza y español, nace española", a mãe encontra-se ajoelhada e, como a espanhola anterior, olha em direção a Virgem. Segura, em seu colo, um bebê envolto por um pano branco e uma manta preta e vermelha. O pai, como um típico espanhol, trajava o estilo bourbônico, ou seja, casacos com botões decorativos nos punhos e na frente, que permitem a visualização do colete sem mangas e bordado. A camisa era branca, com rendas nos punhos e, por vezes, possuíam jabot ${ }^{9}$. As calças eram na altura do joelho, com meias que chegavam até essa altura e presas por botões na cintura. Os sapatos possuíam presilhas de prata e as perucas eram brancas, com dois cachos nas orelhas e um laço atrás segurando o resto do cabelo (YTURBIDE; GAGE, 1990, p. 76; VOSS, 2015, p. 261). Ele segura uma bengala em sua mão esquerda, contribuindo para a demonstração de que era da elite.

Já a última cena do primeiro bloco, "de negro y español, nace mulatto", difere das outras pela espacialidade representada e pela organização familiar em que os

\footnotetext{
8 "That hairstyle, called melena, consisted of a fringe of hair around the face with long sideburns reaching below the shoulders, and the rest of the head shaved" (CLINE, 2015, p. 228).

${ }^{9} \mathrm{Um}$ ornamento colocado sobre o peito de camisas ou blusas, feito de rendas ou do mesmo tecido da peça.
} 


\section{artigos}

\section{A Importância da Indumentária nas Pinturas de Castas}

integrantes se encontram. O pai exerce afazeres que destoam da sua casta e do seu gênero, ou seja, ele prepara alimentos em uma cozinha, uma função feminina em um espaço considerado impróprio para as altas castas (SCOTT, 2005, p. 74). Para isso, veste roupas apropriadas: calça vermelha, camisa branca simples e dobrada nas mangas; um avental comprido e um lenço na cabeça. Sua esposa, sentada no chão, veste roupas de alto padrão, ocupando uma posição de poder em relação ao homem, por não realizar as tarefas. O filho dessa união remete à mestiçagem indesejada e tal fato aparece em sua posição no quadro: ele está longe dos pais (CLINE, 2015, p. 230231). Como demonstração de que era um mulatto, ele segura um chicote (CLINE, 2015, p. 231). Nessa trama, toda a composição refere-se a desarmonia, buscando aludir à negatividade da mestiçagem com pessoas negras.

Na cena cinco, "de española y mulatto, nace morisca", o pai usa trajes típicos, como o chicote na mão. É possível observar uma jóia em seu sapato, adereço comum para os homens de alto padrão, já que os adornos comumente usados pelos homens eram as fivelas, botões e presilhas de sapato (MIRA, 2007, p. 156-157). Sua esposa, ao meio, como elo familiar, representa harmonia e remete a positividade desse relacionamento, diferentemente da quarta representação (CLINE, 2015, p. 232).

A cena subsequente, "de morisca y español nace albino torna atrás", apresenta uma família sentada em um divã. O pai usa uma longa túnica de tecido rico em bordados dourados, sendo este também utilizado em seu chapéu. A mãe, olhando em direção à Virgem de Guadalupe, é a figura feminina mais luxuosa da obra. O olhar de súplica em direção à Virgem fica expressivo nessa cena, pois o seu filho regrediu na lógica da hierarquia das castas, sendo que o termo torna-atrás era pensado para filhos de pais brancos que nasceram negro. Pensava-se que, caso ocorresse um relacionamento interracial com negro, mesmo que o filho nascesse branco, depois de 


\section{artigos}

Giovanna de Assis Bareli

quatro gerações, o herdeiro seria negro:

Se o cruzamento original foi entre espanhol e negro, a quarta geração de retorno produz o fenômeno de atavismo, em que aparece um indivíduo com características totalmente negroides, impossibilitando assim o retorno a raça branca. Se trata de um caso de torna-atrás, segundo a terminologia fiel. A sucessão é, em todos os casos, mulatto-morisco-albino-torna-atrás. (MORENO NAVARRO, 1969, p. 207, tradução nossa) ${ }^{10}$.

Esse termo não era uma autodefinição, mas utilizado como insulto e como uma classificação não biológica (OLIVEIRA, 2018, p. 14). Entretanto, a criança parece ser bem aceita pela família, estando perto dos pais na composição e utilizando roupas do estilo bourbônico e que seguem a mesma linha da do pai, pelo chapéu que utiliza (CLINE, 2015, p. 233).

Na sétima cena, "de mestiza y indio, nace lobo", o esposo utiliza uma veste indígena azul, possivelmente um quexquemitl, sandálias e cabelo ao estilo melena, que configura que ele é um indígena cristianizado ${ }^{11}$. Ele traz consigo dois peixes que remetem a sua profissão. A mãe, por sua vez, está com uma veste tipicamente mestiza, que pode ser percebida pelo seu xale de tecido leve e transparente (YTURBIDE; GAGE, 1990, p. 77). As mestizas, incluídas nessa categorização, tinham como característica o rebozo, um véu de algodão. Os véus eram uma obrigação das leis coloniais para todas as mulheres, mas as mestizas não podiam usar longos e trabalhados xales, como as espanholas, e pequenos, como os das criollas (YTURBIDE;

\footnotetext{
${ }^{10}$ No original: "Si el cruzamiento originario fue entre español y negra, a la cuarta generación de retorno se produce un fenómeno de atavismo, según el cual aparece un individuo con características totalmente negroides, quedando asi interrumpido el retorno a la. raza blanca. Se trataría de un caso de torna atrás, según la terminología fielmente repetida. La sucesión es, en todos los casos, mulatomorisco-albino-torna atrás"

${ }_{11}$ Percebe-se que o indígena representado na primeira cena é configurado como bárbaro na lógica que utiliza poucas roupas, adereços nativos e um longo cabelo. Os outros dois indígenas vestem roupas mais ocidentais, possuem o corte melena e utilizam sapatos, o que remete à cristianização (CLINE, 2015, p. 228).
} 


\section{artigos}

\section{A Importância da Indumentária nas Pinturas de Castas}

GAGE, 1990, p. 77).

Por fim, a última cena, "de Yndia y Lobo, nace Yndio", se passa em um ambiente aberto, algo comum para a representação das castas mais baixas (CARRERA, 2003, p. 28). Atrás de uma panela com um líquido branco, possivelmente o pulque, uma mulher usa um vestido e um xale parecido com o da mestiza da cena anterior. Os dois homens - sendo que o sentado só veste um short e o outro está com short e uma camisa azul - bebem o líquido e descontraem. Não é certo qual é o pai e o filho. A representação dessa bebida é importante, pois ela era considerada um mal da colônia pela embriaguez e confusões que causavam (KATZEW, 2004, p. 144-146).

Para complementar a análise descritiva, na parte inferior, em uma espécie de tigela, há dezessete elementos da flora, representados como natureza morta e que eram desconhecidos pela maioria dos europeus. Há a representação de um abacaxi, bem no centro da composição, uma fruta que remete à realeza e cujo símbolo era compreendido muito bem (SCOTT, 2005, p. 74). A descrição das frutas está em náuatle e espanhol, um elemento inovador de Luis de Mena (CLINE, 2015, p. 239-240) e que traz pensamentos importantes: o artista, por trazer uma descrição na língua indígena, alude à questão do criollismo, mas também dialoga com o público da arte exótica por trazer elementos únicos e inusitados, algo desejável para os compradores europeus (CLINE, 2015, p.244-246).

\section{A Indumentária na pintura de castas}

As pinturas de castas, na segunda metade do século XVIII, com o advento das leis que pretendiam o controle da sociedade e de um desejo de maior distinção social, passaram a representar as castas com diferentes vestimentas. A indumentária representada é aquela pautada nas leis coloniais, mas não necessariamente oferecem 


\section{artigos}

Giovanna de Assis Bareli

a representação fiel do que acontecia, já que o gênero das pinturas de castas busca a representação de uma sociedade idealizada e positiva em relação a harmonia e hierarquização racial.

Atentando-se para a análise das vestimentas, ela pode ser dividida seguindo a taxonomia da sociedade de castas, como realizado por Voss: dos espanhóis, das castas mais altas, castas mais baixas e indígenas (VOSS, 2015, p. 261). Contudo, alguns elementos são partilhados: quase a totalidade das vestimentas, aqui exemplificadas pelo quadro Castas, bebem da Reforma Bourbônica, um elemento que também auxilia na determinação da época de produção das obras.

As diversas castas portavam peças da vestimenta espanhola (SÁNCHEZ, 2013, p.8), mas a diferença era perceptível no material empreendido:

O status social era sinalizado através de diferenças sutis na textura, padronização e qualidade do tecido; nos métodos usados para prender roupas; no grau de elaboração de prendedores de roupas, como botões e fivelas; e em ornamentação (ou sua ausência) com bordados, fitas, guirlandas, fios trançados, broches e outras joias (Deagan, 2002; Fisher 1992: 54-61 apud VOSS, 2015, p. 256-257, tradução nossa) ${ }^{12}$.

Segundo o quadro de Mena, podemos perceber isso na diferença de textura e caimento dos vestidos das espanholas e das outras personagens, como as mestizas. A própria ornamentação do tecido é diferente, sendo a das castas mais baixas maior e mais grosseira. Isso de fato acontece, já que as castas mais altas, associadas com o sangue indígena, se vestiam segundo os trajes bourbônicos já descritos, mas com roupas mais folgadas e com materiais mais baratos (VOSS, 2015, p. 261).

\footnotetext{
12 No original: "Social status was signaled through subtle differences in the texture, patterning, and quality of fabric; in the methods used to fasten garments; in the degree of elaboration of garment fasteners such as buttons and buckles; and in ornamentation (or its absence) with embroidery, ribbons, garlands, braided thread, broaches, and other jewelry"
} 


\section{artigos}

\section{A Importância da Indumentária nas Pinturas de Castas}

As castas mais baixas, por sua vez, não utilizavam o estilo espanhol, ou quando o faziam, eram retratados utilizando roupas sujas e em péssimas condições (VOSS, 2015, p. 261), uma maneira de construir um discurso de salientação das castas mais altas como privilegiadas e desejadas na lógica da hierarquia. Normalmente, portavam vestimentas associadas ao trabalho que realizavam, como podemos ver na cena sete do quadro de Mena. Em geral, eram calças e camisas simples, sem ornamentos e de tecido liso, sendo uma mistura entre a roupa indígena e a colonial (VOSS, 2015, p. 261; ORTIZ, 2018, p. 223).

Os objetos incluídos nas cenas desse grupo auxiliavam na compreensão da classificação racial e do trabalho empreendido, como aventais, caixas, bacias e alimentos (CARRERA, 2003, p. 77; 83). É também o caso dos mulattos, em que o chicote era indispensável para a sua caracterização, assim como o rebozo era para as mestizas.

Os indígenas, no entanto, eram normalmente retratados utilizando roupas típicas e roupas limpas, diferentemente das castas mais baixas (YTURBIDE; GAGE, 1990, p. 77). A vestimenta mais simbólica era o huipil, uma peça feita "a partir de vários pedaços de tecido feito à mão, com uma abertura no pescoço e que ficava frouxamente envolto sobre o corpo" (VOSS, 2015, p. 257, tradução nossa) ${ }^{13}$. As mulheres, por baixo do huipil ou quexquemitl, utilizavam saias de algodão com partes de tecido decorado e camisas. As joias utilizadas por elas eram gargantilhas de coral e brincos de prata (YTURBIDE; GAGE, 1990, p. 77). Outras representações do feminino aparecem com o mesmo estilo, porém com tecidos mais elaborados e ornamentados, aludindo para a elite indígena e o casamento entre espanhóis (VOSS, 2015, p. 261).

\footnotetext{
${ }^{13}$ No original: "The huipil was a flowing garment sewn from several lengths of handwoven cloth, with a neck opening to accommodate the head. It was worn loosely draped over the body"
} 


\section{artigos}

\section{Giovanna de Assis Bareli}

Algumas dissonâncias aparecem no gênero, quando, por exemplo, as castas mais altas utilizam elementos indígenas. Tal fato pode ser compreendido como uma forma de retomada de um passado glorioso, o que é comum com a ascensão do criollismo (SÁNCHEZ, 2013, pp. 8-9). O inverso também é percebido, no caso de outras castas, que se vestiam como os espanhóis, principalmente aqueles que alcançavam uma ascensão econômica e buscavam adentrar nas classes mais altas. Essa questão é comum nas pinturas de castas do final do século XVIII (SÁNCHEZ, 2013, p. 9). Dessa forma, percebe-se que as roupas também são agentes de construção e negociação da identidade e uma forma de se posicionar politicamente (VOSS, 2015, p. 253).

\section{Conclusões}

As enunciações descritivas acima procuraram demonstrar que a indumentária é um fator discursivo importante para a composição das pinturas de castas. De maneira geral, os códigos vestuários são elementos ricos para se compreender o comportamento e imaginário de uma sociedade. No caso da Nova Espanha, foram pautados pelas leis sumptuárias, as quais buscavam ordenar, classificar e disciplinar as práticas sociais e o corpo colonial (SÁNCHEZ, 2013, p. 4; CARRERA, 2003, pp. 110125). Além disso, eram baseados nas relações comerciais, regulamentos militares e doutrina religiosa, juntamente com costumes sociais e moda.

As roupas, "como um meio pela qual as identidades sociais são inculcadas e naturalizadas no corpo" (BOURDIEU, 1984; BUTLER, 1990, 1993a; COHN 1996 apud VOSS, 2015, p. 253, tradução nossa) ${ }^{14}$, se tornam, assim, a exteriorização visível da identidade. Isso exprime que o ato pessoal de se vestir estava acoplado na política do Império, como parte da organização social, sendo compreendido como elemento da

\footnotetext{
${ }^{14}$ No original: "is a means through which social identities are inculcated and naturalized in the body"
} 


\section{artigos}

\section{A Importância da Indumentária nas Pinturas de Castas}

construção e negociação da identidade (VOSS, 2015, p. 253). Logo, a indumentária apreendida nesse artigo reflete uma prática social contextualizada, de uma política hierárquica do governo colonial do século XVIII, funcionando como representante visual da hierarquia estamental, um símbolo de identidade coletiva (ORTIZ, 2018, p. 224) e uma chave de compreensão para o universo colonial (SÁNCHEZ, 2013, p. 3).

É fundamental perceber que a posição do corpo também é parte notável da encenação. No caso do quadro de Mena, as mulheres que olham em direção à Virgem são aquelas que possuem filhos de castas menores que os dos pais, em um sentido de orar para protegê-los. O filho, longe da família, é um mestizo, provavelmente não aceito por sua família, pela sua linhagem. A última cena, com dois homens bebendo sentados na rua, alude que eles são de uma casta mais baixa e por isso estão mais propensos a se deixarem levar pela bebida. O local em que eles se encontram também é fundamental e deve ser incluído na análise; quase a maioria das castas altas são representadas em um ambiente fechado e doméstico, sem nenhum complemento, algo característico desse tipo de representação (CARRERA, 2003, p. 101; OLSON, 2009).

Nas pinturas de castas, as roupas cumprem bem a função de criar identidade visual, uma vez que se insere a indumentária como um símbolo, tornando-as uma forma de distinção entre as castas e um dos fatores de construção visual da calidad entre elas (CARRERA, 2003, p.135). É possível visualizar em absoluto esta diferenciação em quadros que apresentam diversas castas, como é o caso do quadro "Castas", que apresenta oito cenas de castas. Mesmo sendo incomum por vários aspectos, esta obra ainda segue as diretrizes do gênero e apresenta uma sociedade ideal, hierarquizada e estratificada. Neste caso, Mena traz mais castas entre a mestiçagem de indígenas e espanhóis, as ditas castas mais altas e que teriam alguma chance de se 


\section{artigos}

\section{Giovanna de Assis Bareli}

tornarem um dia espanhóis ${ }^{15}$. As espanholas do quadro estão todas ao estilo bourbônico; as mestizas e os mulattos utilizam objetos de identificação; e os indígenas são representados tanto de uma forma bárbara, quanto hispanizada. É possível perceber as diferenças de caimento e de tecidos entre as diferentes personagens, algo que se relaciona com a sua aquisição financeira. Um fato interessante é o menino torna-atrás, da sétima cena, que se veste à luz da moda espanhola e, assim, percebe-se que ele é aceito pelos pais (OSLON, 2009, pp. 320-321). É certo que, como uma regulamentação, haviam modos de negociá-la, seja aqueles que desejavam reivindicar um passado indígena, seja aqueles que, em ascendência financeira, buscavam escalar visualmente na sociedade com o uso de vestimentas mais finas e designadas para a elite (SÁNCHEZ, 2013, p. 9).

Nesse sentido, é certo que as pinturas de castas não podem ser compreendidas como a vitrine de uma realidade, mas representam um discurso presente no imaginário social e que foi a base da política colonial. Assim, enquanto um agente visual, buscavam legitimar e retomar uma ordenação já confusa, representando também os discursos de poder colonial (KATZEW, 2004, pp. 200-204).

As pinturas foram amplamente exportadas como um produto exótico e fazem parte de uma classificação do iluminismo do século XVIII (OSLON, 2009, pp. 311-312). Entretanto, internamente, servem, também, para a visibilidade da complexa

\footnotetext{
15 Segundo a classificação mais comumente utilizada nas pinturas de castas: “De español e india nace mestiza; de español y mestiza nace castiza; de español y castiza, española; de español y negra, mulato; de español y mulata, morisco; de español y morisca, alvina; de español y alvina, tornatrás; de español y tornatrás, tente en el aire; de indio y negra, nace cambujo; de cambujo e india, lobo; de lobo e india, albarazado; de albarazado y mestiza; barcino; de barcino e india, zambaigo; de mestizo y castiza, chamizo; de mestizo e india, coyote; de lobos, cambujos y coyote es gente fiera y de raras costumbres" (Ajofrin, p.59 apud ESTRADA DE GERLERO, 1994, p. 82)/ "Según Basarás, si los espanoles se mezclaban sólo com indígenas, la sangre de éstos se podía purificar y volver a ser española, pero si la mezcla era de español o indígena con negro nunca se podía purificar y retornar a ser española o indígena" (KATZEW, 2004, p. 185)
} 


\section{artigos}

\section{A Importância da Indumentária nas Pinturas de Castas}

autoimagem da colônia e para o advento de certa consciência criolla, por sua escolha do que seria representado e apresentado nessas pinturas (OSLON, 2009, pp. 311-312; KATZEW, 2004, pp. 202-203). É pela chave do criollismo que o quadro de Castas é aqui analisado, seja pela inclusão do símbolo identitário mais importante para esse grupo, a Virgem de Guadalupe, seja pela forma como o México, a flora e as personagens estão colocadas.

Portanto, percebe-se que as pinturas de castas possuem como sentido a tentativa de educação visual ${ }^{16}$ e de uma retomada simbólica do discurso colonial de hierarquização. O corpo é um fator de disciplinamento dessas políticas, seja pela vestimenta, seja pelos lugares e afazeres que realiza. As pinturas expressam sentimentos ambíguos, pois, ao mesmo tempo que expressam a reafirmação da sociedade de castas e de um produto de exportação na lógica do exótico e da classificação, também expressam o limiar do sentimento criollo de orgulho da nação e de criação de uma identidade única (OSLON, 2009, pp. 311-312).

\section{Referências Bibliográficas}

\section{Fonte}

MENA, Luis. "Castas" 1750, óleo sobre tela. $119 \times 103 \mathrm{~cm}$. Collection of the Museo de America, Madrid. (inventory number 00026)

\section{Artigos e livros}

Boyer, Richard. "Negotiating Calidad: The Everyday Struggle for Status in Mexico." Historical Archaeology, vol. 31, no. 1, 1997, pp. 64-73. Disponível em:

\footnotetext{
${ }^{16}$ Segue a proposta das imagens serializadas, uma ferramenta muito utilizada para a educação visual na doutrinação cristã (Cf. KATZEW, 2004; OSLON, 2009).
} 


\section{artigos}

Giovanna de Assis Bareli

www.jstor.org/stable/25616518. Acesso em: 07 ago 2020

CARRERA, Magali Marie. Imagining identity in New Spain: race, lineage, and the colonial body in portraiture and casta paintings. Austin, TX: University of Texas Press, 2003. 188 p., il. (Joe R. and Teresa Lozano Long series in Latin American and Latino art and culture). ISBN 9780292712454 (enc.).

CLINE, Sarah. Guadalupe and the Castas: The Power of a Singular Colonial Mexican Painting. Mexican Studies, Santa Barbara, v. 31, n. 2, p.218-247, jun. 2015. Disponível em: $\quad$ Lhttp://www.history.ucsb.edu/wp-content/uploads/Guadalupe-and-theCastas.pdf>. Acesso em: 06 ago 2020

EBERT, Anne. La representación de las américas coloniales en los cuadros de castas. Scientia: Revista do Centro de Pesquisa da Universidade Ricardo Palma. n. 10, v. 10, 2008, pp.139-152. Disponivel

em: https://www.academia.edu/32298503/ La representaci\%C3\%B3n de las Am\%C3\%A9 ricas_coloniales en los cuadros de castas. Scientia_Revista_del_Centro de Investiga ciones de la Universidad Ricardo Palma 102008 139-152. Acesso em: 06 ago. 2020

ESTRADA DE GERLERO, Elena Isabel. Las pinturas de castas, imágenes de una sociedad variopinta. In: México en el mundo de las colecciones de arte, Volume 4. México: Nueva España, 1994. p. 79-114.

. The Representation of 'Heathen Indians' in Mexican Casta Painting. In: KATZEW, Ilona (org.). New World Orders: casta painting and colonial latin america. Newyork: Americas Society Art Gallery, 1996. p. 42-57.

FLORESCANO, Enrique. Memória mexicana. Coautoria de Raul Velazquez. 2. ed. México, DF: Fondo de Cult. Económica, c1994. 604p., il. (Sección de obras de historia). ISBN 9681639995 (enc.).

GRUZINSKI, Serge. O Pensamento Mestiço. São Paulo, SP: Companhia das Letras, 2001, c1999. 398 p., il. ISBN 8535901922 (broch.).

KATZEW, Ilona. La pintura de castas: representaciones raciales en el México del siglo XVIII. Madrid: Turner, 2004. 329 p., il. ISBN 9788475066387 (broch.)

MIRA, Letizia Arbeteta. Precisiones Iconográficas sobre Algunas Pinturas de la colección del Museo de América, basadas en el estudio de la joyería representada. Anales del Museo de América, n. 15, 2007, pp 141-171. Disponível em: 


\section{artigos}

A Importância da Indumentária nas Pinturas de Castas

<https://dialnet.unirioja.es/servlet/articulo?codigo=2572556>. Acesso em: 29 jul 2020

MORENO NAVARRO, Isidoro. Un aspecto del mestizaje americano: El problema de la terminología. Revista Española de Antropología Americana, vol IV, 1969, pp 201 217. Disponivel em: <https://idus.us.es/bitstream/handle/11441/41980/26695-267141-PB.pdf?sequence=1>. Acesso em: 17 mar 2020

OLIVEIRA, Juliana Proenço de. Colonialismos e discursos raciais: as castas de Luis de Mena e o Criollismo no México do Século XVIII. Ícone: revista brasileira de história da arte, Rio Grande do Sul, v. 3, n. 3, p.8-25, 2018. Semestral. Disponível em: $<$ https://seer.ufrgs.br/icone/article/view/85529/51053>. Acesso em: 12 jan. 2020.

OLSON, Christa. "Casta Painting and the Rhetorical Body." In: Rhetoric Society Quarterly, vol. 39, no. 4, 2009, pp. 307-330. Disponível em:<www.jstor.org/stable/40647265>. Acesso em 27 jan. 2020.

ORTIZ, Lorenzo Silva. Castas y posición social: un cuadro de mestizaje como reflejo del poder en la sociedad novohispana del siglo XVIII. Faces de Clio: Revista Discente do Programa de Pós-Graduação em História - UFJF, Juiz de Fora, v. 8, n. 4, p.214-226, JulDez 2018. Semestral. Disponível em: <http://www.ufjf.br/facesdeclio/files/2014/09/8_L4_Lorenzo-Silva-Ortiz-ArtigoLivre_214_226.pdf>. Acesso em: 15 jan. 2020.

SÁNCHEZ, Victória Luján. Representaciones del vestir en la pintura de castas: el indumento como indicador en el marco de un modelo social estamentario. In: IBARRA,A; CASETTA, G. (ed.). Representación en Ciencia y Arte. Vol 4, Editora Brujas, 2013. p. 573-584.

SCHWARTZ, Stuart B.. Colonial identities and the sociedad de castas. Colonial Latin American Review, [s.l.], v. 4, n. 1, p.185-201, jan. 1995. http://dx.doi.org/10.1080/10609169508569846.

SCOTT, Nina M.. Measuring Ingredients: Food and Domesticity in Mexican Casta Paintings. Gastronomica, [s.I.], v. 5, n. 1, p.70-79, fev. 2005. University of California Press. http://dx.doi.org/10.1525/gfc.2005.5.1.70.

VOSS, Barbara L.. Fashioning the colonial subject: clothing. In: __. The Archaeology of Ethnogenesis: Race and Sexuality in Colonial San Francisco Stanford: Stanford University, 2015. p. 253-261.

YTURBIDE, Teresa Castelló; GAGE, Thomas. La indumentaria de las castas del 


\section{artigos}

Giovanna de Assis Bareli

mestizaje. Artes de México, Nueva Epoca, n. 8, 1990, pp. 72-78. Disponivel em: https://www.jstor.org/stable/pdf/24326832.pdf?refreqid=excelsior\%3A8ef47e7fb6c9a 87fe1999a7917b22e6e. Acesso em: 06 ago 2020 